\title{
Research on High-quality Development of Manufacturing Enterprises
}

\author{
Zhu Wei ${ }^{1, a}$ Xu Yunfei ${ }^{1, b}$ \\ ${ }^{1}$ State Grid Energy Research Institute Co., Ltd. Beijing, China
}

\begin{abstract}
Through the analysis of the opportunities and challenges faced by the development of manufacturing enterprises, this paper proposes that the promotion of high-quality development is common trend driven by the current development of China' manufacturing industry. This paper also refines the connotation, basic principles and overall ideas of high-quality development, and puts forward specific implementation paths and guarantee measures for manufacturing enterprises, providing reference and inspiration for manufacturing enterprises to achieve high-quality development.
\end{abstract}

\section{Introduction}

After more than 40 years of rapid development, China's manufacturing industry foundation has been improved increasingly, digitalization and automation has been improved steadily, the ability of scientific and technological innovation has been enhanced continuously, and production scale has increased significantly. China has become the world's largest manufacturing country [1]. However, China's manufacturing industry is still "big but not strong", there are many problems such as insufficient basic research, low overall efficiency, structural imbalance between supply and demand, lagging brand building, weak technological innovation, and insufficient innovative talents. Therefore, China needs to put the highquality development of manufacturing in a more prominent position, and promote the high-quality development of manufacturing enterprises unswervingly, in order to meet the urgent needs of building a strong manufacturing country and revitalizing the manufacturing industry.

\section{Development situation analysis of manufacturing enterprises}

\subsection{The new requirements faced by manufacturing enterprises}

China's economy has shifted from the stage of high-speed growth to the stage of high-quality development. The state has issued a series of policy measures and important measures to promote high-quality development, such as the Guiding Principles on the Implementation of Quality Improvement Actions by the Central Committee of the Chinese Communist Party and the Principles on Promoting High-Quality Development of the Central
Committee of the Chinese Communist Party. The Manufacturing industry is the foundation of building a powerful country, the main body of the real economy, and is related to the overall development of high-quality economic development. Chinese General Secretary Xi Jinping has repeatedly emphasized that the high-quality development of the manufacturing industry should be placed in a more prominent position, actively integrating into a new round of technology and industrial revolution, making high-quality development the main tone of the development of the manufacturing industry.

\subsection{The new opportunities faced by manufacturing enterprises}

The new round of scientific and technological revolution and industrial transformation is accelerating the reconstruction of the global innovation landscape. The United States launched the "Advanced Manufacturing Partnership Program" and issued policy documents such as the "Advanced Manufacturing Leadership Strategy of the United States"; Germany started the "Industry 4.0 Strategic Plan" and released the "National Industrial Strategy 2030"; China put forward "Made in China 2025", and comprehensively implemented the strategy of a strong manufacturing country, promoting China's basic industrialization by 2025, and entering the rank of a strong manufacturing country [2]. China's manufacturing industry could make the full use of this development opportunity to strengthen the high-quality development of manufacturing and enhance core competitiveness.

\subsection{The new challenges faced by manufacturing enterprises}

Manufacturing industry faces the following challenges: Firstly, the enterprise's willingness in basic research is low, weaking the original innovation ability making the

azhuwei@sgeri.sgcc.com.cn bxuyunfei@sgeri.sgcc.com.cn 
shortcomings of basic research unsolved. and the ability in basic research needs to be strengthened. Secondly, the value connotation of business brand has not been realized, and the brand construction is relatively backward. The number of invention patents, average life expectancy and number of brands obviously falls behind those of developed countries. Moreover, the manufacturing industry lacks competitiveness in $\mathrm{R} \& \mathrm{D}$, design, project contracting, marketing and other parts linked with high added value. There is still internal structural contradictions in the manufacturing industry, and the industrial structure needs to be optimized. Finally, it is difficult for the total amount and structure of talent team to meet the requirements of high-quality development, and the constraints of innovative talents are increasingly prominent.

\section{Typical experience of high-quality development of manufacturing enterprises}

Through combing and summarizing the typical experience of the central enterprises in promoting high-quality development, it is found that the high-quality development of manufacturing enterprises is mainly reflected in the four aspects of top-level design, management mechanism, technological innovation, and collaborative mechanism.

\subsection{In terms of top-level design}

In order to promote the manufacturing enterprises to expand from quantity and scale to improve quality and efficiency, CNBM has proposed three strategies of "innovation-driven, green development, and international cooperation", which clarifies the strategic positioning of "the leader of industry integration, the innovator of industrial upgrading, and the pioneer of international production capacity cooperation", to achieve the "threestep" goal of high-quality development; CRRC attaches great importance to top-level design and focuses on "digitalization, networking and intelligence", to establish a multi-level and multi-form strategic cooperation mechanism, and accelerate the development of "internationalization, diversification, high-end, digitalization and collaboration". DEC insists on strategic orientation and value-driven. Organically link strategic objectives and operational indicators, combine benchmarking results with continuous improvement, formulate solutions in a targeted manner, and ensure the strategic landing.

\subsection{In terms of management mechanism}

CNBM has proposed the "three precision management" rules, which focus on reducing organization, level and redundancy to achieve organizational refinement, focus on cost reduction, quality improvement to achieve refined management, and focus on price cost-effectiveness, zero inventory and sales to achieve lean operation; SGCC promotes high-quality development of the electrical equipment by optimizing and adjusting management models and mechanisms, promoting collaboration across the entire industrial chain, strengthening the construction of production management systems, and playing a supporting role in management innovation ; CHALCO strengthens reform efforts, formulates comprehensive reform plans with traction, implements reform reforms, optimizes the Group's management and control model, accelerates the diversification of corporate equity, liberalizes the internal operating mechanism, and stimulates power and vitality at all levels .

\subsection{In terms of technological innovation}

CRRC relies on major national key core technology research projects, continuously improves the collaborative, open and integrated technological innovation system, and continues to increase investment in technological innovation, especially basic forward-looking common technology research and development, and supports the "going out" of rail transit equipment. Patent protection system to speed up the internationalization of rail transit product standards; CHALCO starts with an innovative incentive mechanism, seizes key links and important areas, and inspires various types of talents and cadres and employees; DEC actively participates in the construction of manufacturing National innovation platforms such as innovation centers, industrial technology innovation centers, and key laboratories play a leading role in the industry.

\subsection{In terms of coordination mechanism}

CRRC correctly handles the local and overall, immediate and long-term relationships, builds a multi-level, multidimensional, and internally and externally collaborative development platform, and promotes the benign and winwin development of all aspects of business, regions, and industrial chains Coordinated development pattern of overall planning, division of responsibilities, differentiated development, orderly competition, and resource sharing. SGCC promotes the coordinated development of "intelligent design, intelligent production, and intelligent products", and breaks the information barriers between design, production, and products to achieve information penetration and improve collaboration efficiency.

\section{The idea of High-quality development for manufacturing enterprises}

\subsection{The connotation of high-quality development}

"High-quality development of manufacturing industry" is composed of multiple concepts such as "manufacturing", "enterprise", "high quality" and "development". By reading a lot of relevant literature and conducting many discussions [3-4], this paper holds that High-quality development of manufacturing refers to taking high-level, high-value and high-quality as the development goal of 
enterprises, taking systematic top-level planning for industrial development as the premise, taking quality and efficiency as the value orientation, enhancing innovation ability as the core driving force, taking high-quality technology and management as the starting point, running through all aspects of manufacturing activities, such as design, production, sales, service, etc., to achieve the best economic value and social value of the entire industrial chain.

\subsection{The Basic principles of high-quality development of manufacturing enterprises}

- Quality first: To adhere to product quality as the lifeline to promote the development of the manufacturing industry, strengthen corporate quality responsibility, vigorously promote the development of quality change, efficiency change and power change, and take the development path of improving quality and efficiency.

- Innovation-driven: To adhere to putting scientific and technological innovation at the core of the overall development of the manufacturing industry, improve the system environment conducive to innovation, take the development path of innovation-driven development, and achieve breakthroughs in core technologies and key equipment.

- Structural optimization: To adhere to structural adjustment as the key link to promote highquality development of manufacturing industry, optimize industrial spatial layout, deeply implement the supply side structural reform of manufacturing industry, and achieve the goal of removing the low-end, promoting the middle end and creating the high-end.

- Talent-oriented: To adhere to innovative talents as the basis to promote the high-quality development of the manufacturing industry, establish and improve scientific and reasonable mechanism for selecting, employing and educating people, build a manufacturing team with excellent quality and reasonable structure development route.

\subsection{General idea of high-quality development of manufacturing enterprises}

Facing the new generation of information technology revolution and industrial revolution, it is the general trend for manufacturing enterprises to promote high quality development. This paper proposes that manufacturing enterprises need to be based on the principle of "quality first, innovation driven, structural optimization, talent oriented", taking the development of a systematic toplevel planning industry as the premise, and taking quality and efficiency as the value orientation. The dual-core driving mechanism of technical high quality and management high quality are established throughout design, production, sales and other manufacturing activities. It is based on information technology and intelligent manufacturing technology, and provides basic resource protection from the two key elements of talents and equipment, specifically shown in Figure 1.

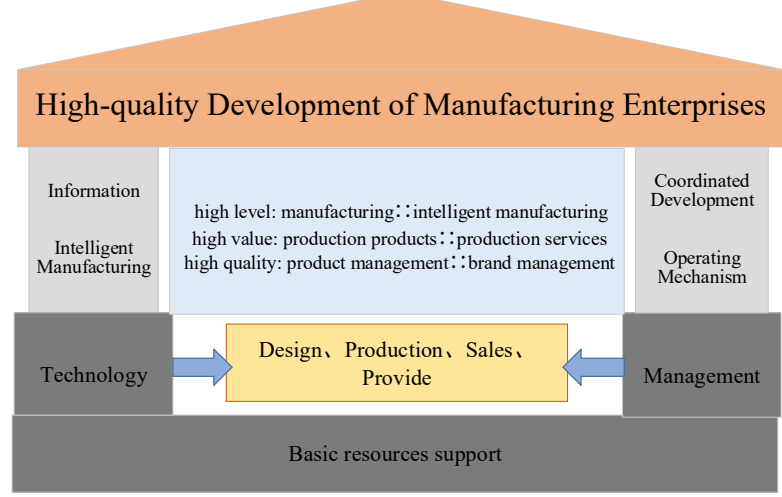

Fig1. High quality development framework of manufacturing enterprises

In terms of technical support, it mainly enhances the hard power of information and intelligent manufacturing; in terms of management support, it enhances the soft power of synergy development and operating mechanism; in terms of resource support, it mainly improves the guarantee ability of innovative talents and advanced equipment, and realizes the overall leap from manufacturing to intelligent manufacturing (high level), from production products to production services (high value), and from product management to brand management (high quality).

\section{Implementation path of high-quality development of manufacturing enterprises}

\subsection{Focus on improving technical hard power}

Manufacturing enterprises need to deepen information technology and intelligent manufacturing technology, especially pay close attention to core basic components, advanced basic processes, key basic materials and industrial technology foundation and other basic capabilities, enhancing the hard power of manufacturing and promoting the transformation and upgrading of manufacturing enterprises [5].

- In terms of information, information technology can be integrated into product design, $\mathrm{R} \& \mathrm{D}$, production, sales and other links, promoting the in-depth application of the entire process of intelligent manufacturing, creating an industrial Internet integration development platform, and realizing intelligent manufacturing technology, products and overall solutions to support the construction of a new industrial ecosystem.

- In terms of intelligent manufacturing, it is necessary for manufacturing enterprises to promote the use of advanced molding technology and processing methods, intelligent production, focus on the implementation of key technology research and development and domestic substitution of the project, and comprehensively 
improve the intelligent level of manufacturing enterprises.

\subsection{Focus on improving management soft power}

Through promoting the coordination and operation mechanism of departments and industrial chains, playing a management support role, it can promote the highquality development of manufacturing enterprises.

- In terms of coordinated development, on the one hand, manufacturing enterprises need to promote the coordinated development of various departments, determine the functional positioning and division of responsibilities of each department, and comprehensively strengthen cooperation between departments; on the other hand, it is also urgent to promote the coordinated development of the industrial chain, which can extend the value chain, especially focusing on the downstream customer service value-added, to create a manufacturing industry ecosystem.

- In terms of operating mechanism, according to the characteristics of the industry, design operating subsystems that are suitable for their own development, such as operating, technological innovation, and finance, so that the company's business activities can be coordinated, orderly, and efficiently operated, and enhance internal vitality and external adaptability.

\subsection{Focus on improving resource guarantee capabilities}

By cultivating innovative talents, developing or purchasing advanced manufacturing equipment and other basic resources, manufacturing enterprises could continue to consolidate the manufacturing resource base and boost high-quality development.

- In terms of cultivating innovative talents, it is of great import to establish a multi-channel and multi-level talent training and introduction mechanism, explore the establishment of a perfect medium- and long-term incentive mechanism, and mobilize the enthusiasm and creativity of business operators and technical personnel, and provide personnel guarantee for the high-quality development of enterprises.

- In terms of advanced equipment, it is also vital for companies with independent $\mathrm{R} \& \mathrm{D}$ capabilities to increase $\mathrm{R} \& \mathrm{D}$ investment, persistently carry out core technology research, seize the initiative of industrial development, and strive to localize key equipment. For companies with weak independent research and development capabilities, they need to actively participate in research and development, purchase more advanced equipment, improve labor productivity and product added value.

\section{Conclusions and recommendations}

Facing new opportunities and challenges, China's manufacturing industry and enterprises need to take highlevel, high-value and high-quality as their development goals, establish a dual core driving mechanism of "highquality technology and high-quality management", which runs through all aspects of manufacturing activities such as design, $\mathrm{R} \& \mathrm{D}$, production and sales, and provide basic resource guarantee from two key elements of talents and equipment. From the aspects of technological innovation, management innovation, industrial structure, talent allocation and other aspects, we should formulate guarantee measures for high-quality development, so as to promote the real vitality of manufacturing industry and enterprises to achieve high-quality development.

In the process of promoting technological innovation, manufacturing enterprises should focus on optimizing the technological innovation system, increasing investment in scientific research and development, and strengthening core technology research. In the process of promoting management innovation, manufacturing enterprises should focus on consolidating the foundation of management innovation, improving operating mechanism innovation and exploring high quality development of new models; in the process of optimizing the industrial structure, manufacturing enterprises should focus on the transformation from manufacturing to intelligent manufacturing, product supply to product and service transformation, product operation to brand operation; in the process of optimizing the talent allocation process, manufacturing enterprises should focus on strengthening Talent team building, improving employee quality awareness, and improving the incentive assessment mechanism.

\section{References}

1. JIN Bei. Study on the "High-Quality Development" Economics [J].CHINA INDUSTRIAL ECONOMICS, 2018(04), pp. 5-18.

2. WANG Wei. A Study on the Measurement and Evaluation of the High-quality Development of China's Economy[J]. East China Economic Management, 2020(34), pp. 1-9.

3. Zhu, X. D., 2012, "Undestanding China's Growth: Past, Present and Future", Journal of Economic Perspectives, Vol. 26, No. 4, pp.103-124.

4. Hanlon W W. Necessity Is the Mother of Invention: Input Supplies and Directed Technical Change[J].Econometrica, 2015, 83(1):67-100.

5. Mlachila M., Tapsoba R., Tapsoba S.J.A., 2017, A Quality of Growth Index for Developing Countries: A Proposal[J]. Social Indicators Research, 134(2), $675 \sim 710$. 